\title{
Ring chromosome 15 syndrome
}

INSERM

\section{Source}

INSERM. (1999). Orphanet: an online rare disease and orphan drug data base. Ring chromosome 15 syndrome. ORPHA:96177

Ring chromosome 15 is a rare chromosomal anomaly syndrome, with a highly variable phenotype, characterized by pre- and/or postnatal growth retardation, variable intellectual disability, short stature, dysmorphic features (microcephaly, triang ular facies, frontal bossing, hypertelorism, ear anomaly, broad nasal bridge, highly arched palate, micrognathism), hand and feet anomalies (e.g. brachydactyly, clinodactyly, syndactyly), and multiple hyperpigmented and/or hypopigmented spots. Severe phenotypes present with cardiac abnormalities and/or renal malformations. Other reported features include hypotonia, speech delay, talipes equinovarus, and genital anomalies (cryptorchidism and hypospadias). 